\begin{tabular}{|c|c|}
\hline \multirow{3}{*}{ 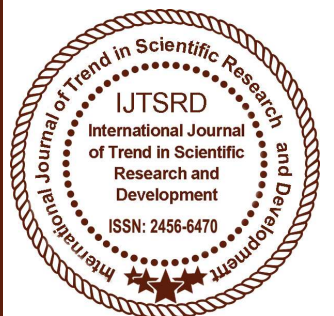 } & $\begin{array}{l}\text { International Journal of Trend in Scientific } \\
\text { Research and Development (IJTSRD) }\end{array}$ \\
\hline & International Open Access Journal \\
\hline & ISSN No: 2456 - 6470 | www.ijtsrd.com | Volume - 2 | Issue - 2 \\
\hline
\end{tabular}

\title{
Oblong Mean Prime Labeling of Some Tree Graphs
}

\author{
Mathew Varkey T K \\ Department of Mathematics, T K M College of \\ Engineering, Kollam, India
}

\author{
Sunoj B S \\ Department of Mathematics, Government Polytechnic \\ College, Attingal, India
}

\begin{abstract}
The labeling of a graph, we mean assign some integers to the vertices or edges (or both) of the graph. Here the vertices of the graph are labeled with oblong numbers and the edges are labeled with mean of the end vertex labels. Here the greatest common incidence number (gcin) of a vertex of degree greater than one is defined as the greatest common divisor of the labels of the incident edges. If the gcin of each vertex of degree greater than one is 1 , then the graph admits oblong mean prime labeling. Here we characterize some tree graphs for oblong mean prime labeling.
\end{abstract}

Keywords : Graph labeling, oblong numbers, prime graphs, prime labeling, trees.

\section{INTRODUCTION}

All graphs in this paper are finite trees. The symbol $V(G)$ and $E(G)$ denotes the vertex set and edge set of a graph $\mathrm{G}$. The graph whose cardinality of the vertex set is called the order of $\mathrm{G}$, denoted by $\mathrm{p}$ and the cardinality of the edge set is called the size of the graph $\mathrm{G}$, denoted by q. A graph with p vertices and q edges is called a $(\mathrm{p}, \mathrm{q})$ - graph.

A graph labeling is an assignment of integers to the vertices or edges. Some basic notations and definitions are taken from [1], [2] , [3] and [4]. Some basic concepts are taken from [1] and [2]. In [5], we introduced the concept of oblong mean prime labeling and proved that some path related graphs are oblong mean prime graphs. In [6] and [7], we proved that some snake graphs and cycle related graphs admit oblong mean prime labeling. In this paper we investigated the oblong mean prime labeling of some tree graphs.

Definition: 1.1 Let $\mathrm{G}$ be a graph with $\mathrm{p}$ vertices and $\mathrm{q}$ edges. The greatest common incidence number (gcin) of a vertex of degree greater than or equal to 2, is the greatest common divisor(gcd) of the labels of the incident edges.

Definition: 1.2 An oblong number is the product of a number with its successor, algebraically it has the form $\mathrm{n}(\mathrm{n}+1)$. The oblong numbers are $2,6,12,20$,

\section{Main Results}

Definition 2.1 Let $\mathrm{G}$ be a graph with $\mathrm{p}$ vertices and q edges . Define a bijection

$\mathrm{f}: \mathrm{V}(\mathrm{G}) \rightarrow\{2,6,12,20$,----------------- $\mathrm{p}(\mathrm{p}+1)\}$ by $\mathrm{f}\left(\mathrm{v}_{\mathrm{i}}\right)=i(i+1)$, for every i from 1 to $\mathrm{p}$ and define a $1-1$ mapping $f_{o m p l}^{*}: \mathrm{E}(\mathrm{G}) \rightarrow$ set of natural numbers $\mathrm{N}$ by $f_{o m p l}^{*}(u v)=\frac{f(u)+f(v)}{2}$. The induced function $f_{o m p l}^{*}$ is said to be an oblong mean prime labeling, if the gcin of each vertex of degree at least 2, is one. 
Definition 2.2 A graph which admits oblong mean prime labeling is called an oblong mean prime graph.

Definition 2.3 Let $G$ be the graph obtained by joining 3 pendant edges to each vertex of a path $P_{n}$. $G$ is denoted by $\mathrm{P}_{\mathrm{n}} \odot 3 \mathrm{~K}_{1}$.

Theorem: 2.1 The graph $P_{n} \odot 3 K_{1}$ ( $n$ is a positive integer greater than 2) admits oblong mean prime labeling.

Proof : Let $\mathrm{G}=\mathrm{P}_{\mathrm{n}} \odot 3 \mathrm{~K}_{1}$ and let $\mathrm{v}_{1}, \mathrm{v}_{2},----------------, \mathrm{v}_{4 \mathrm{n}}$ are the vertices of $\mathrm{G}$.

Here $|\mathrm{V}(\mathrm{G})|=4 \mathrm{n}$ and $\quad|\mathrm{E}(\mathrm{G})|=4 \mathrm{n}-1$.

Define a function $\mathrm{f}: \mathrm{V} \rightarrow\{2,6,12,--------------, 4 n(4 n+1)\}$ by

$$
f\left(v_{i}\right)=i(i+1), i=1,2,-----, 4 n \text {. }
$$

Clearly $\mathrm{f}$ is a bijection.

For the vertex labeling $\mathrm{f}$, the induced edge labeling $f_{o m p l}^{*}$ is defined as follows

$f_{o m p l}^{*}\left(v_{4 i-3} v_{4 i-2}\right)$

$f_{\text {ompl }}^{*}\left(v_{4 i-3} v_{4 i-1}\right)$

$f_{\text {ompl }}^{*}\left(v_{4 i-3} v_{4 i}\right)$

$f_{\text {ompl }}^{*}\left(v_{4 i-3} v_{4 i+1}\right)$

Clearly $f_{o m p l}^{*}$ is an injection.

gcin of $\left(\mathrm{v}_{4 \mathrm{i}-3}\right)$

$$
=(4 \mathrm{i}-2)^{2} \text {, }
$$$$
=16 \mathrm{i}^{2}-12 \mathrm{i}+3 \text {, }
$$$$
=16 \mathrm{i}^{2}-8 \mathrm{i}+3 \text {, }
$$

$=16 i^{2}-4 i+4$,

$$
\begin{aligned}
& i=1,2,-\cdots--n . \\
& i=1,2,-\cdots, n . \\
& i=1,2,-\cdots \\
& i=1,2,-\cdots
\end{aligned}
$$

$$
\begin{aligned}
& =\mathrm{g} \mathrm{c} \mathrm{d} \text { of }\left\{f_{o m p l}^{*}\left(v_{4 i-3} v_{4 i-2}\right), f_{o m p l}^{*}\left(v_{4 i-3} v_{4 i-1}\right)\right\} \\
& =\mathrm{g} \mathrm{c} \mathrm{d} \mathrm{of}\left\{(4 \mathrm{i}-2)^{2}, 16 \mathrm{i}^{2}-12 \mathrm{i}+3\right\} \\
& =\mathrm{g} \mathrm{c} \mathrm{d} \text { of }\{(4 \mathrm{i}-2),(4 \mathrm{i}-2)(4 \mathrm{i}-1)+1\} \\
& =1,
\end{aligned}
$$

So, gcin of each vertex of degree greater than one is 1 .

Hence $\mathrm{P}_{\mathrm{n}} \odot 3 \mathrm{~K}_{1}$ admits, oblong mean prime labeling.

Example 2.1 : Illustration of the above theorem with the graph $\mathrm{P}_{4} \odot 3 \mathrm{~K}_{1}$

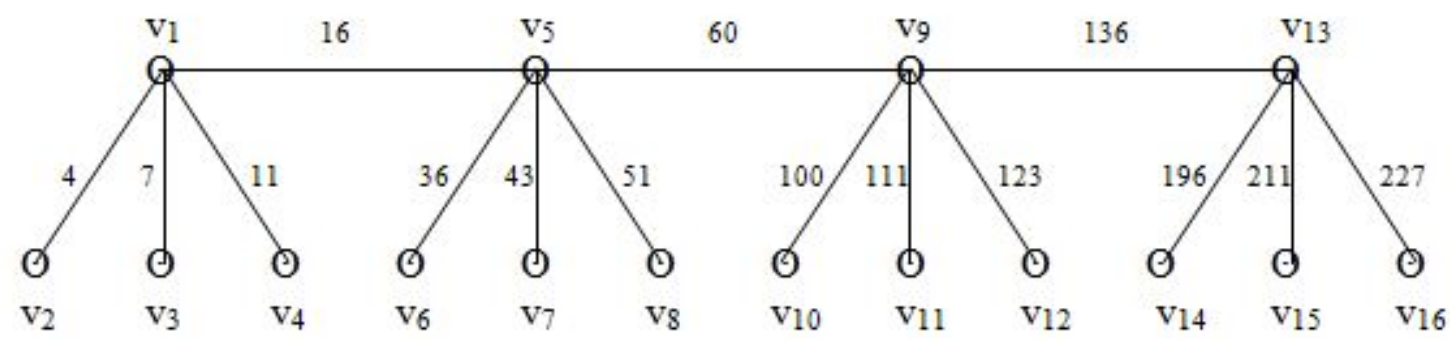

Fig -2.1

Definition 2.4 Let $G$ be the graph obtained by joining 2 pendant edges to each internal vertex of a path $P_{n}$. $G$ is denoted by $T_{w}(n)$ and is called twig graph

Theorem: 2.2 Twig graph $\mathrm{T}_{\mathrm{w}}(\mathrm{n})$ ( $\mathrm{n}$ is a positive integer greater than 2 ) admits oblong mean prime labeling.

Proof : Let $\mathrm{G}=\mathrm{T}_{\mathrm{w}}(\mathrm{n})$ and let $\mathrm{v}_{1}, \mathrm{v}_{2},---------------, \mathrm{v}_{3 n-4}$ are the vertices of $\mathrm{G}$.

Here $|\mathrm{V}(\mathrm{G})|=3 \mathrm{n}-4$ and $|\mathrm{E}(\mathrm{G})|=3 \mathrm{n}-5$.

Define a function $\mathrm{f}: \mathrm{V} \rightarrow\{2,6,12,---------------,(3 n-4)(3 n-3)\}$ by

$$
f\left(v_{i}\right)=i(i+1), i=1,2,------, 3 n-4 .
$$

Clearly $f$ is a bijection.

For the vertex labeling $\mathrm{f}$, the induced edge labeling $f_{o m p l}^{*}$ is defined as follows 


$\begin{array}{lll}f_{\text {ompl }}^{*}\left(v_{i} v_{i+1}\right) & =(\mathrm{i}+1)^{2}, & \mathrm{i}=1,2,------------, \mathrm{n}-1 . \\ f_{\text {ompl }}^{*}\left(v_{n-i} v_{n+2 i-1}\right) & =\frac{(n+2 i-1)(n+2 i)+(n-i)(n-i+1)}{2}, & \mathrm{i}=1,2,------------, \mathrm{n}-2 . \\ f_{\text {ompl }}^{*}\left(v_{n-i} v_{n+2 i}\right) & =\frac{(n+2 i)(n+2 i+1)+(n-i)(n-i+1)}{2}, & \mathrm{i}=1,2,------------, \mathrm{n}-2 .\end{array}$

Clearly $f_{o m p l}^{*}$ is an injection. gcin of $\left(\mathrm{v}_{\mathrm{i}+1}\right)$

$$
\begin{aligned}
& =\mathrm{g} c \mathrm{~d} \text { of }\left\{f_{\text {ompl }}^{*}\left(v_{i} v_{i+1}\right), f_{o m p l}^{*}\left(v_{i+1} v_{i+2}\right)\right\} \\
& =\mathrm{g} \mathrm{cd} \text { of }\left\{(\mathrm{i}+1)^{2},(\mathrm{i}+2)^{2}\right\} \\
& =\mathrm{g} \mathrm{cd} \text { of }\{\mathrm{i}+1, \mathrm{i}+2\} \\
& =1, \quad \mathrm{i}=1,2,-------------, \mathrm{n}-2
\end{aligned}
$$

So, gcin of each vertex of degree greater than one is 1 .

Hence $T_{w}(n)$ admits, oblong mean prime labeling.

Theorem: 2.3 Star graph $\mathrm{K}_{1, \mathrm{n}}$ ( $\mathrm{n}$ is a positive integer greater than 2 ) admits oblong mean prime labeling.

Proof :Let $\mathrm{G}=\mathrm{K}_{1, \mathrm{n}}$ and let $\mathrm{v}_{1}, \mathrm{v}_{2},---------\mathrm{v}_{\mathrm{n}+1}$ are the vertices of $\mathrm{G}$.

Here $|\mathrm{V}(\mathrm{G})|=\mathrm{n}+1$ and $|\mathrm{E}(\mathrm{G})|=\mathrm{n}$.

Define a function $\mathrm{f}: \mathrm{V} \rightarrow\{2,6,12,------(n+1)(n+2)\}$ by

$$
f\left(v_{i}\right)=i(i+1), i=1,2,----, n+1 .
$$

Clearly $f$ is a bijection.

For the vertex labeling $\mathrm{f}$, the induced edge labeling $f_{\text {ompl }}^{*}$ is defined as follows

$f_{o m p l}^{*}\left(v_{1} v_{i+1}\right)$

$$
=\frac{(i+1)(i+2)+2}{2}
$$

$\mathrm{i}=1,2$,

,- n.

Clearly $f_{\text {ompl }}^{*}$ is an injection.

gcin of $\left(\mathrm{v}_{1}\right)$

$$
\begin{aligned}
& =\mathrm{g} \mathrm{c} \mathrm{d} \text { of }\left\{f_{o m p l}^{*}\left(v_{1} v_{2}\right), f_{o m p l}^{*}\left(v_{1} v_{3}\right)\right\} \\
& =\mathrm{g} \mathrm{c} \mathrm{d} \text { of }\{4,7\}=1 .
\end{aligned}
$$

So, gcin of each vertex of degree greater than one is 1 .

Hence $\mathrm{K}_{1, \mathrm{n}}$ admits, oblong mean prime labeling.

Theorem: 2.4 Bi -star graph $\mathrm{B}(\mathrm{m}, \mathrm{n})(\mathrm{m}, \mathrm{n}$ are positive integer greater than 1$)$ admits oblong mean prime labeling.

Proof :Let $\mathrm{G}=\mathrm{B}(\mathrm{m}, \mathrm{n})$ and let $\mathrm{v}_{1}, \mathrm{v}_{2},---------\mathrm{v}_{\mathrm{m}+\mathrm{n}+2}$ are the vertices of $\mathrm{G}$.

Here $|\mathrm{V}(\mathrm{G})|=\mathrm{m}+\mathrm{n}+2$ and $|\mathrm{E}(\mathrm{G})|=\mathrm{m}+\mathrm{n}+1$.

Define a function $\mathrm{f}: \mathrm{V} \rightarrow\{2,6,12,------,(m+n+2)(m+n+3)\}$ by

$$
\mathrm{f}\left(\mathrm{v}_{\mathrm{i}}\right)=\mathrm{i}(\mathrm{i}+1), \mathrm{i}=1,2,-----\mathrm{,}, \mathrm{n}+2 \text {. }
$$

Clearly $\mathrm{f}$ is a bijection.

For the vertex labeling $\mathrm{f}$, the induced edge labeling $f_{\text {ompl }}^{*}$ is defined as follows
$f_{o m p l}^{*}\left(v_{m+1} v_{i}\right)$
$=\frac{(m+1)(m+2)+i(i+1)}{2}$,
$\mathrm{i}=1,2,-----------, \mathrm{m}$.
$f_{o m p l}^{*}\left(v_{m+1} v_{m+2}\right)$
$=(\mathrm{m}+2)^{2}$.
$f_{\text {ompl }}^{*}\left(v_{m+2} v_{m+i+2}\right)$
$=\frac{(m+2)(m+3)+(m+i+2)(m+i+3)}{2}$,
$i=1,2,-----------, n$.

Clearly $f_{o m p l}^{*}$ is an injection.
gcin of $\left(\mathrm{v}_{\mathrm{m}+1}\right)$
$=\operatorname{g~c~d~of~}\left\{f_{o m p l}^{*}\left(v_{m} v_{m+1}\right), f_{o m p l}^{*}\left(v_{m+1} v_{m+2}\right)\right\}$
$=\mathrm{gcd}$ of $\left\{(\mathrm{m}+1)^{2},(\mathrm{~m}+2)^{2}\right\}=1$.
gcin of $\left(\mathrm{v}_{\mathrm{m}+2}\right)$
$=\operatorname{g~c~d~of~}\left\{f_{o m p l}^{*}\left(v_{m+2} v_{m+3}\right), f_{o m p l}^{*}\left(v_{m+1} v_{m+2}\right)\right\}$
$=\mathrm{gcd}$ of $\left\{(\mathrm{m}+3)^{2},(\mathrm{~m}+2)^{2}\right\}=1$.

So, gcin of each vertex of degree greater than one is 1 .

Hence $\mathrm{B}(\mathrm{m}, \mathrm{n})$ admits, oblong mean prime labeling. 
Definition 2.5 Let $G$ be the graph obtained by joining $n$ pendant edges to one of the end vertex of a path $P_{m}$. $G$ is denoted by $\mathrm{CT}(\mathrm{m}, \mathrm{n})$ and is called coconut tree graph.

Theorem: 2.5 Coconut tree graph CT $(\mathrm{m}, \mathrm{n})$ ( $\mathrm{m}$ is a positive integer greater than 2 and $\mathrm{n}$ is a positive integer greater than 1) admits oblong mean prime labeling.

Proof :Let $\mathrm{G}=\mathrm{CT}(\mathrm{m}, \mathrm{n})$ and let $\mathrm{v}_{1}, \mathrm{v}_{2},----------------, \mathrm{v}_{\mathrm{m}+\mathrm{n}}$ are the vertices of $\mathrm{G}$.

Here $|\mathrm{V}(\mathrm{G})|=\mathrm{m}+\mathrm{n}$ and $|\mathrm{E}(\mathrm{G})|=\mathrm{m}+\mathrm{n}-1$.

Define a function $\mathrm{f}: \mathrm{V} \rightarrow\{2,6,12,-----------,(m+n)(m+n+1)\}$ by

$$
f\left(v_{i}\right)=i(i+1), i=1,2,------m+n \text {. }
$$

Clearly $f$ is a bijection.

For the vertex labeling $\mathrm{f}$, the induced edge labeling $f_{o m p l}^{*}$ is defined as follows

$f_{\text {ompl }}^{*}\left(v_{i} v_{i+1}\right) \quad=(\mathrm{i}+1)^{2}$,

$f_{o m p l}^{*}\left(v_{m} v_{m+i+1}\right)$

$$
=\frac{(m+i+1)(m+i+2)+(m)(m+1)}{2}, \quad \sqrt{\mathrm{i}}=1,2,---\cdot-------, \mathrm{n}-1 .
$$

Clearly $f_{o m p l}^{*}$ is an injection.

gcin of $\left(\mathrm{v}_{\mathrm{i}+1}\right)=1$,

So, gcin of each vertex of degree greater than one is 1 .

Hence $\mathrm{CT}(\mathrm{m}, \mathrm{n})$ admits, oblong mean prime labeling.

Definition 2.6 Let $G$ be the graph obtained by joining $n$ pendant edges to the end vertices of path $P_{n}$. $G$ is denoted by $\operatorname{DCT}(n, n, n)$ and is called double coconut tree graph.

Theorem: 2.6 Double coconut tree graph $\operatorname{DCT}(n, n, n)(n$ is a positive integer greater than 2$)$ admits oblong mean prime labeling.

Proof : Let $G=\operatorname{DCT}(n, n, n)$ and let $v_{1}, v_{2},---$ Rese, $v_{3 n}$ are the vertices of $G$.

Here $|\mathrm{V}(\mathrm{G})|=3 \mathrm{n}$ and $|\mathrm{E}(\mathrm{G})|=3 \mathrm{n}-1$.

Define a function $\mathrm{f}: \mathrm{V} \rightarrow\{2,6,12,---------, 3 \mathrm{n}(3 \mathrm{n}+1)\}$ by

$$
f\left(v_{i}\right)=i(i+1), i=1,2,-----, 3 n \text {. }
$$

Clearly $f$ is a bijection.

For the vertex labeling $\mathrm{f}$, the induced edge labeling $f_{\text {ompl }}^{*}$ is defined as follows
$f_{o m p l}^{*}\left(v_{n+i} v_{n+i+1}\right)$
$=(\mathrm{n}+\mathrm{i}+1)^{2}$,
$f_{o m p l}^{*}\left(v_{n+1} v_{i}\right)$
$=\frac{(n+1)(n+2)+(i)(i+1)}{2}$,
$i=1,2,-\cdots---\cdot n-1$.
$f_{o m p l}^{*}\left(v_{2 n} v_{2 n+i}\right)$
$=\frac{(2 n)(2 n+1)+(2 n+i)(2 n+i+1)}{2}$,
$i=1,2,-\cdots---\cdot n$.
$i=1,2,------------, n$.

Clearly $f_{o m p l}^{*}$ is an injection.

$$
\begin{array}{ll}
\operatorname{gcin} \text { of }\left(\mathrm{v}_{\mathrm{n}+1}\right) & =\mathrm{g} \mathrm{c} \mathrm{d} \text { of }\left\{f_{o m p l}^{*}\left(v_{n} v_{n+1}\right), f_{o m p l}^{*}\left(v_{n+1} v_{n+2}\right)\right\} \\
& =\mathrm{g} \mathrm{c} \mathrm{d} \text { of }\left\{(\mathrm{n}+1)^{2},(\mathrm{n}+2)^{2}\right\}=1 . \quad \mathrm{i}=1,2,-----------, \mathrm{n}-2 . \\
\operatorname{gcin} \text { of }\left(\mathrm{v}_{\mathrm{n}+\mathrm{i}+1}\right) & =1, \\
\operatorname{gcin} \text { of }\left(\mathrm{v}_{2 \mathrm{n}}\right) & =\mathrm{g} \mathrm{c} \mathrm{d} \text { of }\left\{f_{o m p l}^{*}\left(v_{2 n-1} v_{2 n}\right), f_{o m p l}^{*}\left(v_{2 n} v_{2 n+1}\right)\right\} \\
& =\mathrm{g} \mathrm{cd} \text { of }\left\{(2 \mathrm{n})^{2},(2 \mathrm{n}+1)^{2}\right\}=1 .
\end{array}
$$

So, $g c i n$ of each vertex of degree greater than one is 1 .

Hence DCT(n,n,n) admits, oblong mean prime labeling.

Theorem: 2.7 Let $\mathrm{G}$ be the graph obtained by joining 2 pendant edges to the path vertices of the comb graph alternately. $\mathrm{G}$ admits oblong mean prime labeling, if $(n>2)$ is odd and pendant edges start from the first vertex.

Proof :Let $\mathrm{G}$ be the graph and let $\mathrm{v}_{1}, \mathrm{v}_{2},----------------, \mathrm{v}_{3 n+1}$ are the vertices of $\mathrm{G}$.

Here $|\mathrm{V}(\mathrm{G})|=3 \mathrm{n}+1$ and $|\mathrm{E}(\mathrm{G})|=3 \mathrm{n}$. 
Define a function $\mathrm{f}: \mathrm{V} \rightarrow\{2,6,12,----------------,(3 n+2)(3 n+1)\}$ by

Clearly $f$ is a bijection.

$$
f\left(v_{i}\right)=i(i+1), i=1,2,------, 3 n+1 .
$$

For the vertex labeling $\mathrm{f}$, the induced edge labeling $f_{o m p l}^{*}$ is defined as follows

\begin{tabular}{|c|c|c|}
\hline$f_{o m p l}^{*}\left(v_{i+1} v_{2 n+3-i}\right)$ & $=\frac{(2 n+3-i)(2 n+4-i)+(i+2)(i+1)}{2}$, & $i=1,2,-----------, n$. \\
\hline$f_{o m p l}^{*}\left(v_{2 i} v_{2 n+2+i}\right)$ & $=\frac{(2 i)(2 i+1)+(2 n+2+i)(2 n+i+3)}{2}$ & $---\frac{n+1}{2}$ \\
\hline${ }_{o m p l}^{*}\left(v_{2 i+2} v_{3 n+2-i}\right)$ & $=\frac{(2 i+2)(2 i+3)+(3 n+2-i)(3 n-i+3)}{2}$ & $\mathrm{i}=1,2,--\cdot$ \\
\hline $\begin{array}{l}{ }_{\text {ompl }}^{*}\left(v_{i} v_{i+1}\right) \\
\text { learly } f_{o m p l}^{*} \text { is an injection. } \\
\text { cin of }\left(v_{i+1}\right)\end{array}$ & $=(\mathrm{i}+1)^{2}$, & $\mathrm{i}=1,2,-$ \\
\hline
\end{tabular}

So, gcin of each vertex of degree greater than one is 1 .

Hence $\mathrm{G}$ admits, oblong mean prime labeling.

Theorem: 2.8 Subdivision graph of $\operatorname{star} \mathrm{K}_{1, \mathrm{n}}(2<\mathrm{n} \leq 15)$ admits, oblong mean prime labeling.

Proof: Let $\mathrm{G}$ be the graph and let $\mathrm{v}_{1}, \mathrm{v}_{2},----\cdots,-\mathrm{v}_{2 n+1}$ are the vertices of $\mathrm{G}$.

Here $|V(G)|=2 n+1$ and $|E(G)|=2 n$.

Define a function $\mathrm{f}: \mathrm{V} \rightarrow\{2,6,12,------,(2 n+2)(2 n+1)\}$ by

$$
f\left(v_{i}\right)=i(i+1), i=1,2,-----, 2 n+1 .
$$

Clearly $f$ is a bijection.

For the vertex labeling $\mathrm{f}$, the induced edge labeling $f_{o m p l}^{*}$ is defined as follows

$f_{o m p l}^{*}\left(v_{1} v_{2 i}\right)=2 \mathrm{i}^{2}+\mathrm{i}+1$, nternational $J$ ou $\mathrm{i}=1,2,----------, \mathrm{n}$.

$f_{\text {ompl }}^{*}\left(v_{2 i+1} v_{2 i}\right)$

Clearly $f_{o m p l}^{*}$ is an injection.

gcin of $\left(\mathrm{v}_{1}\right)$

$$
=4 i^{2}+4 i+1 \text {, }
$$$$
\mathrm{i}=1,2,-\cdots--\cdot-\cdot
$$

gcin of $\left(\mathrm{v}_{2 \mathrm{i}}\right)$

$=\operatorname{g~c~d~of~}\left\{f_{o m p l}^{*}\left(v_{1} v_{2}\right), f_{o m p l}^{*}\left(v_{1} v_{4}\right)\right\}$

$=\operatorname{gcd}$ of $\{4,11\}=1$.

$=\mathrm{g} \mathrm{cd}$ of $\left\{f_{o m p l}^{*}\left(v_{1} v_{2 i}\right), f_{o m p l}^{*}\left(v_{2 i} v_{2 i+1}\right)\right\}$

$=\operatorname{gcd}$ of $\left\{2 \mathrm{i}^{2}+\mathrm{i}+1,(2 \mathrm{i}+1)^{2}\right\}$

$=\operatorname{gcd}$ of $\left\{2 \mathrm{i}^{2}+\mathrm{i}+1,(2 \mathrm{i}+1)\right\}$

$=1$,

$\mathrm{i}=1,2$,

So, gcin of each vertex of degree greater than one is 1 .

Hence $\mathrm{G}$ admits, oblong mean prime labeling.

\section{References}

1) Apostol. Tom M, Introduction to Analytic Number Theory, Narosa, (1998).

2) F Harary, Graph Theory, Addison-Wesley, Reading, Mass, (1972)

3) Joseph A Gallian, A Dynamic Survey of Graph Labeling, The Electronic Journal of Combinatorics(2016), \#DS6, pp 1 - 408.

4) T K Mathew Varkey, Some Graph Theoretic Generations Associated with Graph Labeling, PhD Thesis, University of Kerala 2000.

5) Sunoj B S, Mathew Varkey T K, Oblong Mean Prime Labeling of Some Path Graphs, Aryabhatta Journal of Mathematics and Informatics, Vol-9, No-1, Pages: 320 - 326, April 2017.

6) Sunoj B S, Mathew Varkey T K, Oblong Mean Prime Labeling of Some Snake Graphs, International Journal on Recent and Innovation Trends in Computing and Communication, Vol-5, No-6, Pages: 5 - 7 , June 2017.

7) Sunoj B S, Mathew Varkey T K, Oblong Mean Prime Labeling of Some Cycle Graphs , Advances in Dynamical Systems and Applications, Vol-12, No-2, Pages: 181 - 186, July 2017 